\title{
Percepção de mulheres encarceradas sobre o acesso à saúde como ferramenta de ressocialização
}

\author{
Women prison inmates' perceptions of access to health as a tool for resocialization \\ Percepción de las mujeres reclusas sobre el acceso a la salud como herramienta de resocialización
}

\author{
Karlayne Reynaux Vieira de Oliveiral; Amuzza Aylla Pereira dos Santos"; Maraysa Jessyca de Oliveira Vieira ${ }^{\prime \prime \prime}$; \\ Elaine Pimentellv; Isabel Comassettov; Jovânia Marques de Oliveira e Silva ${ }^{\text {VI }}$
}

\begin{abstract}
RESUMO
Objetivo: desvelar a percepção das mulheres sobre o acesso aos serviços de saúde como ferramenta do processo de ressocialização. Método: trata-se de um estudo fenomenológico-sociológico, qualitativo, realizado entre novembro de 2018 e novembro de 2019, com 10 mulheres de um estabelecimento prisional feminino de Maceió, Alagoas. Resultados: as participantes possuíam de 22 a 54 anos, ensino fundamental incompleto, pardas, solteiras, já haviam vivenciado a maternidade. Emergiram duas categorias temáticas: percepções do acesso aos serviços de saúde: a invisibilidade das mulheres e acesso aos serviços de saúde como uma ferramenta de ressocialização: elos dilacerados e Trabalho e Educação como alternativa de Fuga do esquecimento, ociosidade e solidão. Conclusão: evidenciou-se a percepção de invisibilidade das mulheres privadas de liberdade e desvinculação do acesso aos serviços de saúde como ferramenta do processo de ressocialização.

Descritores: Assistência à saúde; Saúde da mulher; Prisões; Socialização.
\end{abstract}

\begin{abstract}
Objective: to unveil women's perceptions of access to health services as a tool in the re-socialization process. Method: this qualitative, phenomenological-sociological study was conducted between November 2018 and November 2019 with 10 women at a women's prison in Maceió, Alagoas, Brazil. Results: the participants were 22 to 54 years old, of mixed race, single, had not completed lower secondary school, and had already experienced motherhood. Two thematic categories emerged: "Perceptions of access to health services: women's invisibility" and "Access to health services as a resocialization tool: ties in shreds and Work and Education as an alternative escape route from oblivion, idleness and loneliness. Conclusion: the women deprived of their freedom were found to perceive themselves to be invisible and disconnected from access to health services as a tool in the resocialization process.
\end{abstract}

Descriptors: Delivery of Health Care; Women's Health; Prisons; Socialization.

\section{RESUMEN}

Objetivo: revelar las percepciones de las mujeres sobre el acceso a los servicios de salud como herramienta en el proceso de resocialización. Método: este estudio cualitativo, fenomenológico-sociológico se realizó entre noviembre de 2018 y noviembre de 2019 con 10 mujeres en una cárcel de mujeres en Maceió, Alagoas, Brasil. Resultados: las participantes tenían entre 22 y 54 años, mestizas, solteras, no habían completado el primer ciclo de secundaria y ya habían experimentado la maternidad. Surgieron dos categorías temáticas: "Percepciones del acceso a los servicios de salud: invisibilidad de las mujeres" y "Acceso a los servicios de salud como herramienta de resocialización: lazos en jirones y Trabajo y Educación como vía alternativa de escape al olvido, la ociosidad y la soledad. Conclusión: las mujeres privadas de libertad se percibieron a sí mismas invisibles y desconectadas del acceso a los servicios de salud como herramienta en el proceso de resocialización.

Descriptores: Prestación de Atención de Salud; Salud de la Mujer; Prisiones; Socialización.

\section{INTRODUÇÃO}

A partir da história e modelos prisionais em meados do século XVII e início do século XVIII produziu-se a conclusão de que o sistema era fundamentado na correção dos indivíduos e tentativas de transformação da alma e comportamento para o convívio social. Entretanto, as privações de liberdade continuam não atingindo a função social proposta de ressocialização. A prisão, que deveria estar restrita a privação do direito à liberdade, hoje é muito mais que isso para aqueles que vivenciam a sentença ${ }^{1-2}$.

'Enfermeira. Especialista. Aluna do curso de mestrado. Universidade Federal de Alagoas. Maceió, Brasil. E-mail: Karlayne2006@gmail.com. ORCID: https://orcid.org/0000-0002-8920-5154.

"Enfermeira. Doutora. Professora Adjunta. Universidade Federal de Alagoas. Maceió, Brasil. E-mail: amuzza.santos@gmail.com. ORCID: https://orcid.org/0000-0001-6299-7190. "'Enfermeira. Mestre. Especialista. Universidade Federal de Alagoas. Maceió, Brasil. Email: maraysa_jessyca@hotmail.com. ORCID: https://orcid.org/0000-0002-2539-1795. IVAdvogada. Doutora. Mestre. Professora Adjunta. Universidade Federal de Alagoas. Maceió, Brasil. E-mail: elaine.pimentel@fda.ufal.br. ORCID: https://orcid.org/0000-0001-8632-9488. `Enfermeira. Doutora. Professora Adjunta. Universidade Federal de Alagoas. Maceió, Brasil. E-mail: isabelcomassetto@gmail.com. ORCID: https://orcid.org/0000-0002-2389-9384.

VIEnfermeira. Doutora. Professora Adjunta. Universidade Federal de Alagoas. Maceió, Brasil. E-mail: jovaniasilva@gmail.com. ORCID: https://orcid.org/0000-0001-7452-2651 
Ainda que a punição tenha surgido ao longo dos séculos para recuperação moral dos detentos, este modelo, ao afastar e privar o indivíduo de serviços, inviabiliza a recuperação. Com vistas à população feminina, o crescimento do número de reeducandas chama a atenção para múltiplos problemas que afetam o universo da mulher, tais como, as desigualdades de gênero e as diversas formas de violência que a mulher é exposta e que se multiplicam na prisão e implicam em sérios problemas a saúde desta população ${ }^{3-4}$.

A Lei de Execuções Penais reitera que a assistência ao preso e ao internado é dever do Estado, objetivando prevenir o crime e orientar o retorno à convivência em sociedade. A assistência acima destacada inclui assistir em aspectos materiais, à saúde, jurídica, educacional, social e religiosa ${ }^{5,6}$. Nesta perspectiva busco elucidar a seguinte questão norteadora: Qual a percepção das mulheres encarceradas sobre o acesso aos serviços de saúde como uma ferramenta do processo de ressocialização?

Frente ao exposto, é evidente que a privação de liberdade deve ter na prática a finalidade de devolver a possibilidade de as pessoas reconstruírem sua história gozando de todos os seus direitos. Esta pesquisa tem como objetivo desvelar a percepção das mulheres sobre o acesso aos serviços de saúde como ferramenta do processo de ressocialização.

\section{REFERENCIAL TEÓRICO}

A teoria Fenomenológica de Alfred Schutz defende que a subjetividade tem papel principal fundante do sentido, revelando importante significado a subjetividade como constitutiva social e inerente à auto com preensão objetiva. Seus estudos minuciosos resultaram numa recombinação dos alicerces de uma teoria fenomenológica-sociológica, que recomenda a apreciação das relações sociais mútuas que cercam as pessoas. A vida cotidiana e a forma que as angústias e preocupações vivenciadas pelas pessoas estão interligadas entre seus pares inferindo a relação de subjetividade. A forma de vivenciar uma experiência torna-se o ponto de partida para a fenomenologia social, uma vez que a existência social, a vida presente e a relação interpessoal são características e fatos essenciais para uma análise fenomenológica ${ }^{7-10}$.

\section{MÉTODO}

Trata-se de um estudo fenomenológico-sociológico, qualitativo, com referencial teórico-metodológico fundamentado na fenomenologia Social de Alfred Schutz, realizado em um estabelecimento prisional feminino de Maceió, Alagoas, entre novembro de 2018 e novembro de 2019. Participaram deste estudo 10 mulheres, escolhidas de acordo com a liberação dos profissionais atuantes na instituição prisional, respeitando os critérios de segurança e que atendiam aos critérios de inclusão: mulheres na condição de "julgadas" e que já puderam usufruir da assistência em saúde e foram excluídas do estudo as mulheres que apresentaram algum déficit cognitivo ou comportamental diagnosticado.

A coleta de dados foi caracterizada pela realização da entrevista com questionário semi-estruturado, constituído por questões fechadas que permitiu a caracterização das participantes e duas questões norteadoras: Qual a sua percepção sobre o acesso aos serviços de saúde como uma ferramenta do processo de ressocialização? O que ter acesso aos serviços de saúde representa/significa para você no processo de ressocialização?

Os dados coletados foram categorizados e tipificados, com base nos princípios metodológicos de pesquisa Fenomenológica em Schutz ${ }^{10}: 1$. Atitude desinteressada do observador científico; 2 . Regras de relevância sociológica (Do que/ Quem e onde?); 3. Postulado de coerência lógica (Aproximação, transcrição e desvelar estruturas); 4. Postulado de Interpretação subjetiva (Considerar história biográfica do ator estudado); 5. Postulado da Adequação (Garantia da consistência dos constructos com as falas); 6. Racionalidade lógica científica (Compreensão e análise das categorias).

O estudo foi aprovado pelo Comitê de Ética em Pesquisa da instituição, conforme parecer n. 2.826.927 e CAAE n. 92124418.1.0000.5013, cumprindo as resoluções 466/12 e 510/16, além de obter parecer favorável da Secretaria de Estado de Ressocialização e Inclusão Social (SERIS). Visando personificar as mulheres que participaram deste estudo, foram nomeadas inicialmente com nomes de flores e características mais marcantes, garantindo acima de tudo o anonimato dessas protagonistas.

\section{RESULTADOS E DISCUSSÃO}

As participantes desta pesquisa foram 10 mulheres, na faixa etária de 22 a 54 anos, predominantemente com ensino fundamental incompleto, pardas, solteiras, dentre as participantes, apenas uma não vivenciou a maternidade, variando entre mães com um filho e mais de dois filhos, no momento da entrevista duas estavam gestantes. Relacionado à religião, elas se identificam como evangélicas ou católicas. Com vistas à passagem pelo sistema prisional, a maior parte 
referiu sua primeira passagem, o tempo de reclusão foi de cinco meses até 11 anos, todas exerciam atividades laborais informais antes do aprisionamento.

A categorização a seguir emergiu das tipificações construídas, considerando a situação biográfica e os motivos "por que e para" descritos na Teoria Fenomenológica e que permeiam o mundo das mulheres privadas de liberdade. Nesta fase, cumpriram-se o terceiro Postulado da pesquisa fenomenológica em Schutz que se refere à coerência lógica (aproximação, transcrição e desvelar estruturas) e o quarto Postulado de Interpretação subjetiva (Considerar história biográfica do ator estudado $)^{7,9,10}$.

\section{Percepções do acesso aos serviços de saúde: A Invisibilidade das mulheres}

As percepções das mulheres privadas de liberdade sobre o acesso aos serviços de saúde como algo inerente ao direito constitucional é um discurso controverso e distante do que os avanços legais buscam garantir, as falas revelam percepções de invisibilidade frente às reais necessidades e peculiaridades do universo feminino, principalmente, vivenciando o encarceramento e todas as consequências da privação de liberdade na vida de uma pessoa.

Observa-se que mesmo com o crescimento da população prisional representando menos de $10 \%$ do contingente de presos do país e esses números indicando a necessidade de atenção e preocupação, é evidente a importância de avançar em debates em prol da liberdade das mulheres que permanecem subordinadas a contextos de privações e opressões ${ }^{11}$. Diante desta evidência o significado da invisibilidade é exposto por meio da fala da participante:

Nós que somos mulheres e sofremos muito, somos sensiveis, temos medo, cólicas, choro, fico explosiva, necessitamos de muitas coisas que o sistema nos priva. Em Alagoas nós mulheres somos esquecidas, não temos apoio de ninguém (Girassol sonhadora).

Durante o período em que as mulheres estão institucionalizadas, foi evidente em seus discursos a presença intensa de sentimentos relacionados à tristeza, dor, solidão, abandono, revolta e ansiedade, e esses sentimentos são identificados como agentes estressores que contribuem para o comprometimento da saúde mental dessa população, frente ao exposto, observa-se a carência de ações de saúde em todos os níveis de atenção reconhecidamente como direito e não como regalia ${ }^{12}$, como descrito abaixo:

Pra eu não sentir problema de saúde de vez em quando procurar o médico não faz mal a ninguém, a gente tem esse direito, não aqui, em qualquer outro canto, apesar de eu já tá aqui, eu creio que tenho esse direito pelo menos de pegar uma vitamina (Antúrio Livre).

Os autores do estudo intitulado "A invisibilidade da mulher no sistema prisional brasileiro: esquecidas no tempo $e$ espaço" afirmam que mesmo o número de mulheres sendo muito inferior em relação ao de homens (detentos) elas sofrem certo esquecimento no que diz respeito às ações de políticas pública, ao direito à saúde, seus direitos sexuais e reprodutivos ${ }^{13,14}$. Com relação aos profissionais que viabilizam o acesso aos serviços de saúde, a enfermeira mesmo com todas as suas limitações diárias faz parte da categoria mais mencionada nos discursos de atenção à saúde. Entretanto, as falas descritas abaixo ofertam a oportunidade de desvelar a percepção das carências de assistência em saúde refletidas no discurso de admiração ao trabalho executado por estudantes que realizam ações de educação e promoção de saúde que presentes no imaginário delas refletem o cuidado desejado e esperado, mas que se distanciam da prática vivenciada no cenário carcerário.

Eu sinto orgulho de vocês [estudantes], eu acho lindo, cuidar das pessoas, sem preconceito, as atitudes de chegar perto, tratar, conversar, aqui muitas têm preconceito (Azaleia Falante).

Aqui tem muita mulher, tem que ter mais atendimento, falta atendimento para saúde, com a enfermeira até que tem mais mas mesmo assim é raro, aqui tem muitas pessoas doentes, é importante ter atendimento, tem muitas viciadas e psiquiátricas! (Azaleia Falante).

As experiências das mulheres, assim como a reserva de informações e vivências com vistas ao acesso aos serviços de saúde no sistema prisional, configuram o estoque de conhecimento, onde, por meio dele os sujeitos fundamentam suas ações. A fenomenologia sociológica fundamenta-se no vivenciar a experiência, valoriza a unicidade da vivência, onde, só o ator social, sujeito da ação pode dizer o que pretende sentir na relação com a mesma, onde, toda ação intencional tem o seu significado ${ }^{7,9,10}$.

Dessa forma, é evidente que as reservas de informações dessas mulheres carregam percepções que se distanciam do cerne da enfermagem e do acesso aos serviços de saúde que é "o cuidado", principalmente, a integralidade da atenção à saúde, que constitui o segundo princípio da Política Nacional de Atenção Integral à Saúde as Pessoas Privadas de Liberdade, preconizado por meio das ações de promoção, proteção, prevenção, assistência, recuperação e vigilância em saúde, em diferentes níveis de atenção ${ }^{15}$. 


\section{Acesso aos serviços de saúde como uma ferramenta de ressocialização: Elos dilacerados}

Os constructos revelam a limitação de conhecimento com vistas ao conceito integral de saúde, associando apenas, ao acesso a consultas com profissionais de diferentes áreas, acesso aos exames e entrega de medicações, em muitas ocasiões até o sistema de classificação das mulheres que precisarão de atendimento é feito pelas representantes dos módulos e pela escolha dos agentes para retirarem das celas. Diante desta visão restrita e iniciativas de saúde limitadas, ficou evidente uma desvinculação do acesso aos serviços de saúde como uma das ferramentas do processo de ressocialização.

No sistema prisional o conceito integral de saúde já está diretamente relacionado à doença, o reconhecimento do pilar saúde, como fator fundamental para completa ressocialização, está longe da realidade que as apenadas estão inseridas, algumas mulheres entendem que se suas necessidades são supridas quando precisam e conseguem ser atendidas, têm suas queixas minimizadas, ela já está tendo acesso aos serviços de saúde e recebendo atendimento satisfatório como descrito abaixo:

Aqui eles já estão fazendo, algo melhor pela a gente, examinam, dão medicamento, não reclamo de não ser atendida, não tenho o que reclamar, se estivesse estaria mentindo (Eucalipto silencioso).

Toda vez que precisei de atendimento eu fui atendida, então para mim tá ótimo, sempre me preocupei com a saúde, eu tenho medo de morrer, ai eu fico me examinando (Gipsófila Estudiosa).

Em estudo realizado com 40 mulheres em uma penitenciária do Rio de Janeiro sobre o que as mulheres privadas de liberdade dizem acerca do acesso aos serviços de saúde, os achados coadunam com as evidências apresentadas neste material, onde o serviço de saúde é caracterizado por uma atenção individualizada, curativista ou realizado por livre demanda a mercê de uma classificação que não é realizada por profissionais de saúde, perpassando por dificuldades para esse acesso às atividades relacionadas à saúde ${ }^{16}$. 0 desabafo de “Copo de Leite Doce" revela um pouco do cenário que está inserida:

Para ir para escola é grito, para colocar a farda é grito, para dor é paracetamol, a gente não vê mudança da parte da gerência (Copo de Leite Doce).

Na saúde, o Estado devia ajudar com mais verbas, mais consultas toda semana, tô aqui há 4 anos, nunca tive uma chance de ir num hospital, é muito tempo sem conseguir uma ultrassonografia, tenho problema de coluna e só vivo tomando injeção, na verdade, o sistema gosta mais de quem dar trabalho, peço também visita assistida e nunca tive e nem vi meu irmão, não é porque ele não me ama, eu sei! (Girassol sonhadora).

Estudos com mulheres em situação prisional revelam que "o confinamento da pessoa ao espaço privado contribui para sua invisibilidade uma vez que esta passa a não ser enxergada pelos outros e suas especificidades são destituídas de interesse pelos mesmos". A situação de limitação ao acesso aos serviços de saúde é reflexo das desigualdades entre pessoas de diferentes classes sociais, onde as mulheres encarceradas já vêm desses grupos socialmente marginalizados e vivenciam as restrições de acesso aos serviços de saúde antes do encarceramento e após o mesmo ${ }^{17-19}$.

Tal panorama diverge do imaginário e previsão das políticas públicas que enxergam na condição de aprisionamento uma possibilidade de maior controle e acesso aos serviços de saúde, uma vez que as mulheres se encontram em um ambiente fechado, mais acessíveis aos profissionais de saúde e com a facilidade de acompanhamento da situação de saúde. Para cumprir o seu papel ressocializador as prisões precisariam ser "reinventadas", deveriam deixar de ser um depósito de pessoas com problemas de adaptação social de múltiplas ordens para se tornar um lugar em que elas pudessem ser tratadas dignamente e reaprender a conviver com outras pessoas minimizando os riscos de reincidência 20 .

Acesso aos serviços de saúde como uma ferramenta de ressocialização: trabalho e educação como alternativa de fuga do esquecimento, da ociosidade e solidão.

Com relação às iniciativas de vivência do processo de ressocialização e as formas mais eficazes de atingir a reintegração social, no universo de presídios femininos, os problemas que permeiam estes cenários são ainda maiores. As mulheres ao serem sentenciadas, recebem uma sentença dupla, pelo crime que cometeram e por serem mulheres que carregam consigo suas paixões e motivações criminais, devido aos valores socialmente arraigados, o ideário feminino de "sexo frágil" associado ao título fantasioso do "papel de mulher" transgredido, em que o sistema penal assume o papel domesticador ${ }^{12}$.

As opressões e privações do sistema prisional desenvolve o processo de "mortificação do eu", a partir das constantes humilhações, violências e degradações a que as presas estão sujeitas, dificultando que as presas vejam a prisão como um espaço legítimo de ressocialização. Reafirmando o exposto, Schutz, explica que compreender as condutas dos indivíduos é extrair o significado do que fazem no presente, fizeram no passado e/ou farão no futuro ${ }^{7,9,10}$. 
As percepções evidenciaram que mesmo diante da invisibilidade das mulheres, da desvinculação da saúde com uma das ferramentas de ressocialização e das limitações das iniciativas de ressocialização, elas buscam nas possibilidades de saídas das celas a forma de suprir inúmeras limitações e carências. Segundo Schutz, compreender as condutas dos indivíduos é extrair o significado do que fazem no presente, fizeram no passado e/ou farão no futuro ${ }^{7,9,10}$.

Elas colocam para trabalhar para diminuir a pena e isso motiva, mas quando descobre que está gravida, não pode mais, não tem palestras para gestantes e atenção, e isso prejudica o comportamento, não tem mais motivação (Rosa florida).

Aqui dentro é um novo ensinamento, quem quer, não são todas, observar, ouvir, entender melhor as companheiras mais inteligentes, não é fácil, cada dia que passa aprende mais (Girassol sonhadora).

Em relação às situações de violência vivenciadas na prisão, algumas mulheres referiram que, durante o período da pena, são inúmeras as possibilidades de conviverem com episódios relacionados à violência tanto física quanto psicológica. Diante disso, elas se agarram no trabalho ou na educação como uma oportunidade de esquecer momentaneamente as grades do presidio e tudo que as formas de violências que cercam a privação de liberdade, buscando na família a força que precisa para vivenciar esta fase, conforme descrito nas falas abaixo:

Aqui não tem ressocialização por completa, uma faz todas pagam, muitas se revoltam com isso, mas não quero que minha familia se decepcione, quero provar que mudei, muitas saem e voltam de novo por falta de apoio (Eucalipto silencioso).

As iniciativas de ressocialização representam a possibilidade de interagir com outras pessoas, compartilhar vivências, adquirir conhecimentos e de ressignificar a imagem pessoal, principalmente, frente à família e os filhos. O ser em sua atitude natural compreende o mundo ao interpretar suas próprias experiências e toda compreensão de um objeto fundamentado se volta para aquilo que possui um significado. Neste caso o significado subjetivo direcionado a tentativa de ressignificação da imagem se volta para as oportunidades encontradas por elas para reconstruir suas histórias por meio das iniciativas de ressocialização ${ }^{7}$. 0 discurso abaixo reafirma o exposto:

Eu não quero mais a vida de lá de fora, é maravilhosa a chance que lá fora não tive, erro é permanecer no erro, você tem que querer mudança e acreditar em você, várias meninas querem vir, mas não tem vaga, enquanto outras não querem aprender, vem e só ficam sentadas, só para sair de lá.... Eu fico no trabalho porque o trabalho que vai fazer eu sustentar meu filho, aqui não tem como trabalhar e estudar! (Azaleia falante).

Apesar de o Estabelecimento prisional feminino ter uma boa estrutura física, não contar com celas superlotadas, ter estrutura de saúde com equipe de enfermagem, psicóloga, assistente social e consultas semanais de médico e odontólogo, além das iniciativas laborais e estudo, ainda é muito carente de envolvimento de políticas e gestores que acompanhem e viabilizem a concretização dos projetos nas atividades práticas no cotidiano.

\section{CONCLUSÃO}

A percepção das mulheres evidencia uma desvinculação entre a saúde e a ressocialização, não são perceptíveis as ligações que caracterizam a saúde como pilar fundamental para total ressocialização. A invisibilidade das mulheres também é refletida nas percepções delas acerca dos serviços de saúde ofertados e a possibilidade de ressocialização é enxergada como uma oferta extra do sistema prisional, cabendo a elas a responsabilidade de ser ressocializada e de forma menos expressiva o dever Estado. As iniciativas dos projetos de ressocialização como atividades de educação e trabalho são alternativas usadas como tentativas de fuga das celas, do esquecimento, da solidão e do aprisionamento.

\section{REFERÊNCIAS}

1. Foucault M. Vigiar e punir. R. Ramalhete, trad. 2013.

2. Costa ECP. Enfim, a liberdade: as mulheres e a vivência pós-cárcere [Doctoral dissertation]. Recife: Universidade Federal de Pernambuco; 2011 [cited 2019 Nov 12]. Available from: https://repositorio.ufpe.br/bitstream/123456789/9186/1/arquivo2615_1.pdf

3. Rosa SM, Nunes FC. Instituições prisionais: Atenção psicossocial, saúde mental e reinserção social. Fragmentos de Cultura. 2014 [cited 2019 Nov 12]; 24(1):125-38. DOI: http://dx.doi.org/10.18224/frag.v24i1.3393

4. Diuana V, Ventura M, Simas L, Larouzé B, Correa M. Women's reproductive rights in the penitentiary system: tensions and challenges in the transformation of reality. Ciên. saúde Coletiva [Internet]. 2016 [cited 2019 Nov 12]; 21:2041-50. DOI: https://doi.org/10.1590/1413-81232015217.21632015

5. Sánchez A, Leal MC, Larouzé B. The reality of health in prisons and the challenges involved. Ciên. saúde Coletiva [Internet]. 2016 [cited 2019 Mar 06]; 21(7):1996-97. DOI: https://doi.org/10.1590/1413-81232015217.08682016

6. Ministério da Justiça (Br). Lei no 7.210, de 11 de julho de 1984. Institui a Lei de Execução Penal. Diário Oficial da União. Brasília (DF): 1984 [cited 2019 Mar 06]; Available from: http://www.planalto.gov.br/ccivil 03/leis/l7210.htm

7. Wagner HTR. Sobre fenomenologia e relações sociais: Alfred Schutz. Petrópolis: Vozes; 2012 
8. Zeferino MT, Carraro TE. Alfred schütz: from theoretical-philosophical framework to the methodological principals of phenomenological research. Texto contexto - enferm [Internet]. 2013 [cited 2019 Nov 12]; 22(3):826-34. DOI: http://dx.doi.org/10.1590/S0104-07072013000300032

9. Schutz A. Collected papers I. The problem of social reality. Springer Science \& Business Media, 2012.

10. Schutz A. Bases da fenomenologia. Wagner, H. (Org), 1979.

11. Carvalho DTP, Mayorga C. Contribuições feministas para os estudos acerca do aprisionamento de mulheres. Estudos Feministas [Internet]. 2017 [cited 2019 May 12]; 25(1): 95-112. DOI: http://dx.doi.org/10.1590/1806-9584.2017v25n1p95

12. Santos MVD, Alves VH, Pereira AV, Rodrigues DP, Marchiori GRS, Guerra JVV. Mental health of incarcerated women in the state of Rio de Janeiro. Texto contexto - enferm. (Online) 2017 [cited 2019 Feb 02]; 26(2):e5980015. DOI: https://doi.org/10.1590/0104-07072017005980015

13. Carvalho OF, Jardilino JRL. The invisibility of women in the brazilian prison system, forgotten in time and space. Rev. Educação e Políticas em Debate. 2017 [cited 2019 Mar 19]; 6(2):236-54. DOI: https://doi.org/10.1590/0104-07072017005980015

14. Varikas E. Pária: uma metáfora da exclusão das mulheres. Rev. Bras. de Hist. [Internet]. 1989 [cited 2019 Mar 19]; 9(18):19-28. Available from: https://www.anpuh.org/arquivo/download?ID_ARQUIVO=3847

15. Ministério da Saúde (Br). Portaria Interministerial n. 1, de 2 de janeiro de 2014.Institui a Política Nacional de Atenção Integral à Saúde das Pessoas Privadas de Liberdade no Sistema Prisional (PNAISP) no âmbito do Sistema Único de Saúde (SUS). Diário Oficial da República Federativa do Brasil. Brasília (DF): Ministério da Saúde; 2014a. [cited 2019 Mar 19]; Available from: http://bvsms.saude.gov.br/bvs/saudelegis/gm/2014/pri0001_02_01_2014.html.

16. Santos MV, Alves VH, Pereira AV, Rodrigues DP, Marchiori GRS, Guerra JVV. Access to Health Services: what the women deprived of their liberty say? Rev. enferm. Atual. In Derme [Internet]. 2018 [cited 2020 Jan 05]; 86(24). Available from: https://revistaenfermagematual.com.br/index.php/revista/article/view/94

17. Fertonani HP, Pires DEP, Biff D, Scherer MDA. The health care model: concepts and challenges for primary health care in Brazil. Cên. saúde coletiva [Internet]. [cited 2020 Jan 05]; 20(6):1869-78. DOI: https://doi.org/10.1590/1413-81232015206.13272014

18. Mignon S. Health issues of incarcerated women in the United States. Ciên. saúde coletiva [Internet]. 2016 [cited 2020 Jan 10 ]; 21(7):2051-60. DOI: https://doi.org/10.1590/1413-81232015217.05302016

19. Ferreira BAM, Baía IVM. Gênero e Prisão: os impactos do sistema prisional sobre a desigualdade social e invisibilidade da mulher encarcerada no estado de Alagoas. Revista Espacialidades. 2019 [cited 2020 Jan 10]; 13(1):127-57. Available from: https://periodicos.ufrn.br/espacialidades/article/view/17605/11507

20. Dourado JLG, Alves RSF. Prisoner's health overview: access difficulties to healthcare. Bol. - Acad. Paul. Psicol. [Internet]. 2019 [cited 2020 Jan 10]; 39(96): 47-57. Available from: http://pepsic.bvsalud.org/scielo.php?script=sci_arttext\&pid=S1415711X2019000100006 